Article

\title{
Development of a repair process for manmade structures in space by using aluminium brazing and friction stir spot welding
}

\author{
Tobias Koehler ${ }^{1, *}$, Cheng-Nien $\mathbf{Y u}^{2}$, Kiril Schmidt ${ }^{1}$, Michael Graetzel ${ }^{1}$, Yangyang $\mathbf{W u}^{2}$, \\ Jean Pierre Bergmann ${ }^{1}$, Dusan P. Sekulic ${ }^{2, *}$ \\ ${ }^{1}$ Production Technology Group, Technische Universität Ilmenau, Germany \\ Kiril Schmidt, M.Sc.; kiril.schmidt@tu-ilmenau.de \\ Michael Graetzel, M.Sc.; michael.graetzel@tu-ilmenau.de \\ Prof. Dr.-Ing. habil. Jean Pierre Bergmann; jeanpierre.bergmann@tu-ilmenau.de \\ 2 Department of Mechanical Engineering, Institute for Sustainable Manufacturing, University of Kentucky, \\ United States of America \\ Cheng-Nien Yu, M.Sc.; chengnien.yu@uky.edu \\ Yangyang Wu, B.Sc.; yangyang.wu@uky.edu \\ * Correspondence: Tobias Koehler, M.Sc.; tobias.koehler@tu-ilmenau.de \\ Prof. Dusan P. Sekulic; sekulicd@engr.uky.edu
}

Received: 23.07.2019; Accepted: 11.09.2019

\begin{abstract}
Small-sized parts and micrometeoroids' impacts represent an increasing threat to artificial components/structures. The damages caused by them can be fixed using e.g., mechanical fixture with epoxy adhesive. However, the repair process is costly and only intended for a temporary fixing the penetration. In order to increase the life time of the repair, an approach for a more reliable process using similar materials is needed. The objective of this work is to develop a process for repairing manmade structures in space by generating joint properties similar to the base material. In this work, two approaches for repairing complex structures were considered. The first approach aims to fill a hole using liquid aluminium phases by brazing, and the second approach aims to fill the holes by a solid-state process (friction stir spot welding). In this study, different binding mechanisms of these two approaches were analyzed preliminarily by means of mechanical and/or metallographic characterization under terrestrial, controlled atmosphere conditions. Both concepts are proven feasible under these conditions. It has been shown that it is possible to realize a good filling of the hole with the investigated materials and under selected process conditions with both presented concepts.
\end{abstract}

Keywords: repair; aluminium brazing; friction stir spot welding

\section{Introduction}

The increasing number of space debris and small meteoroids increases the risk of collisions with satellites and other artificial components in space [1,2]. Due to highly developed telescopes and using mathematical calculations, it is possible to predict the collision location and time with larger debris and meteorites and mitigate the catastrophic impacts. The system is limited to a detection of smaller parts, less than $10 \mathrm{~mm}$ in diameter. Hence, there is always a risk that artificial structures can be damaged [3].

The International Space Station (ISS) is located about $400 \mathrm{~km}$ above the Earth's surface, in the Low Earth Orbit (LEO). At this altitude, the smallest parts reach average speeds of $25000 \mathrm{~km} / \mathrm{h}$. If a micro-meteo-roid and/or orbital debris (MMOD) collide with the ISS, it is caught by outer shell, the Whipple shield. The Whipple shield consists of various aluminium and ceramic layers which are intended to pulverize the debris as much as possible to minimize the impact pulse and thus prevent further damage [4]. The outer layer of the shield is called bumper and consists of an up to $4 \mathrm{~mm}$ thick EN AW 6061-T6 aluminium sheet. The inner pressure shell consists of EN AW 2219-T87 or EN AW 2219-T851 [5]. An Example for a damaged outer shell of the ISS can be seen in Fig.1 and Fig. 2. Fig. 1. shows impact damages on the ISS radiator panels and Fig. 2. shows a hole in the mini-pressurization logistics module (MPLM) with a diameter of $1.1 \mathrm{~mm}$. However, if debris damage the aluminium bumper, there must be a safe procedure to restore protection from MMODs. The biggest challenges are to deal with the limited resources and the more difficult physical and atmospheric conditions in space [6]. Due to the open space's corrosive and harmful characteristic, space materials have to be specially treated and coated [7]. Since $90 \%$ of the interior space of the ISS is obstructed by equipment and 
other interiors, repairs must be carried out from the outside [8]. In case of repair, these protective layers must be removed for a short time and reapplied. Impacts on the ISS can be processed using KERMIt (Kit for External Repair of Module Impacts), a process which fills damaged parts with an adhesive epoxy adhesive. KERMIt was developed and designed for temporary repair in 1999. The success of the repair depends on many factors such as the amount of preparatory work, temperature, atmosphere, viscosity, filling position or injection rate. Due to the atmosphere in space, which is toxic for plastics, it is still unclear how long the filling can resist against corrosion [9]. For this reason, repair materials with similar properties and hence, processes which enable a material locking between the outer shell and the repair material should be used.
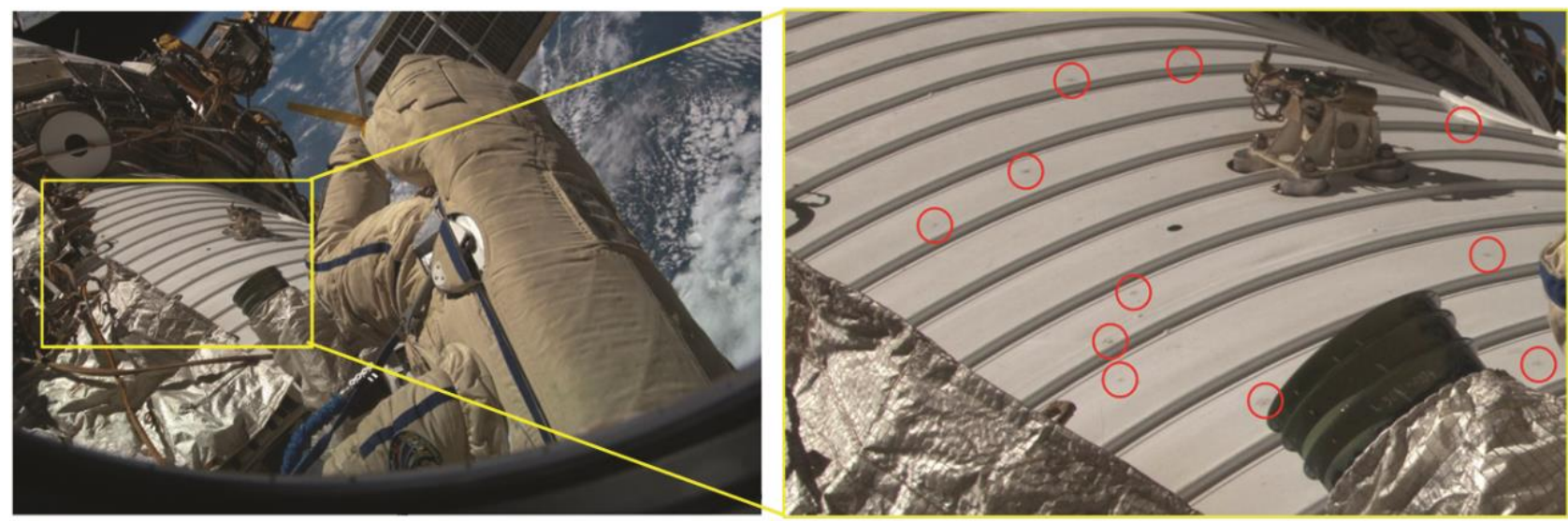

Fig. 1. Impact damages on ISS radiator panels (June 2013) [4]

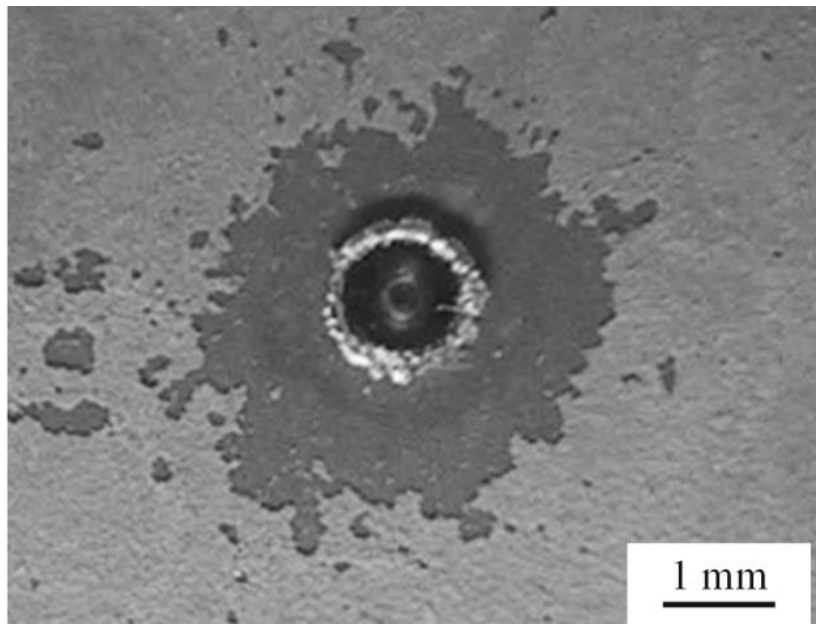

Fig. 2. A hole in the mini-pressurization logistics module (MPLM) with a diameter of $1.1 \mathrm{~mm}$ caused by impact [10]

Against this background, the objective of this investigation is the development of methods based on the use of the similar repair materials, by which damaged artificial structures in space can be repaired by generating a material bonding. The preliminary, feasibility study is conducted under 1-g conditions. The repaired hole should be filled with repair material and should have similar to identical material properties of the base material. In a prior work by Yu et al. [11], a series of repairing tests under terrestrial conditions and controlled non-vacuum atmosphere was performed using aluminium brazing sheets, consisted of Al-Si clad and Al-Mn core alloys. It was concluded that filling a prescribed hole on a brazing sheet may be achieved by surface tension driven molten clad if the hole diameters are within a given limit, depending on the materials and sample dimensions. If a hole size is larger than such a limit, the hole will no longer be filled by surface tension driven capillary flow during an aluminium brazing process.

In this work, two approaches for repairing damaged structures with a material bonding process were considered. The first approach aims to fill a hole using liquid aluminium formed directly on the repair location by brazing. The second approach aims to fill the holes by a solid-state process (friction stir spot welding (FSSW)). In addition to the previous selected EN AW 3003 material, the aluminium alloy EN AW 6061 is included in current study for repair attempts. This investigation focuses on the different binding mechanisms and the advantages and disadvantages of the respective process. In addition, the influence of the brazing and welding parameters on the quality of the repair was analyzed and evaluated. 


\section{Materials and Methods}

For materials used in experimental studies, $0.4 \mathrm{~mm}$ and $0.5 \mathrm{~mm}$ thick samples of EN AW 3003 and EN AW 6061 were prepared as specimens which represent the outer ISS shell with 0.5 to $1.5 \mathrm{~mm}$ holes. As the repair material, 0.4 and $0.5 \mathrm{~mm}$, thick sheets of EN AW 4047 were used. Refer to Table I and Table II for material details. Approaches and experimental setups for both repair methods will be presented in the following section.

Table I. Chemical composition of the used materials according to DIN 573-3:2009 and DIN EN ISO 17672:2017

\begin{tabular}{ccccccccccc}
\hline \multirow{2}{*}{ Material } & & \multicolumn{1}{c}{ Chemical composition [wt.\%] } \\
& Si & Fe & Cu & Mn & Mg & Cr & Zn & Ti & Others & Al \\
\hline EN AW 3003 H14 & 0.6 & 0.7 & $0.05 \div 0.2$ & $1.0 \div 1.5$ & - & - & 0.1 & - & 0.15 & rest \\
EN AW 4047 & $11.0 \div 13.0$ & 0.8 & 0.3 & 0.15 & 0.1 & - & 0.2 & 0.15 & 0.15 & rest \\
EN AW 6061 T6 & $0.4 \div 0.8$ & 0.7 & $0.15 \div 0.4$ & 0.15 & $0.8 \div 1.2$ & $0.04 \div 0.35$ & 0.25 & 0.15 & 0.15 & rest \\
\hline
\end{tabular}

Table II. Mechanical properties of the used materials according to DIN 485-2:2016

\begin{tabular}{cccccc}
\hline Material & $\mathrm{T}_{\text {sol }}\left[{ }^{\circ} \mathbf{C}\right]$ & $\mathbf{T}_{\text {Liq }}\left[{ }^{\circ} \mathbf{C}\right]$ & $\mathbf{R}_{\mathbf{p 0 . 2}}$ [MPa] & $\mathbf{R}_{\mathbf{m}}[\mathbf{M P a}]$ & Hardness [HBS] \\
\hline EN AW 3003 H14 & 643 & 654 & 125 & 145 & 46 \\
EN AW 4047 & 575 & 585 & - & $125 \div 180$ & 71 (TU Ilmenau) \\
EN AW 6061 T6 & 580 & 650 & 240 & 290 & 88 \\
\hline
\end{tabular}

The microstructural characterization of the samples was carried out with an optical microscope with a maximum optical magnification of $\times 1000$. Metallographic photos were prepared by grinding/polishing using 220 grit, 1200 grit, 2400 grit, and 4000 grit $\mathrm{SiC}$ papers. Then the sample surfaces were further polished by $0.04 \mu \mathrm{m}$ colloidal silica. The brazed specimen surfaces were etched by the Keller's reagent. The friction stir spot welded samples were electrolytically anodized according to Barker ( $30 \mathrm{~s} ; 40 \mathrm{~V})$. The cross sections of the FSSW-samples were prepared according to the illustration in Fig. 8b).

Table III. Chemical composition FSSW tool [12]

\begin{tabular}{cccccccccc}
\hline Material & \multicolumn{1}{c}{ Chemical composition [wt.\%] } & & Al & W \\
\hline $\begin{array}{c}\text { Tungsten-Lanthanodixe } \\
\text { (WLa 10) }\end{array}$ & Si & Fe & Cu & Ni & S & C & Cr & Al \\
\hline
\end{tabular}

\section{Approaches and Experimental Setups Aluminium Brazing}

The first approach is to repair a hole utilizing a brazing process in a controlled atmosphere furnace. A typical aluminium brazing process includes heating of both filler and base alumium alloys to the targeted temperature, at which the base alloy stays at a solid state and the filler alloy transforms to the liquid phase, wetting molten aluminium over the base aluminium at a high temperature, and followed by solidification for forming a sound metallic joint after the cooling process. An ideal brazed joint should feature filets with small contact angles and very little topographical alternation/erosion of base alloys.

Two aluminium alloy sheets are selected as the target of repair using a brazing process: (1) aluminium manganese alloy, EN AW 3003, and (2) aluminium magnesium silicon alloy, EN AW 6061. Filler material is an aluminium silicon alloy, EN AW 4047. A sample substrate disk, of a $4 \mathrm{~mm}$ diameter, is extracted from either an EN AW 3003 or an EN AW 6061 source sheet. Both source sheets are $0.4 \mathrm{~mm}$ thick so that any extracted sample disk from both sheets would have the same thickness. All filler disks, extracted from an EN AW 4047 sheet, feature $0.4 \mathrm{~mm}$ of thickness and $1.8 \mathrm{~mm}$ in diameter. For each sample, a hole is prepared by a SiC precise drilling bit and targeted at $0.5 \mathrm{~mm}$ diameter. Controlled atmosphere brazing process was performed to compare brazing Al-Si to Al-Mn and Al-Mg-Si alloys. A potassium fluoroaluminate flux is used for EN AW 4047 on EN AW 3003 brazing tests, which was previously reported as being successful in repairing holes of the EN AW 4045/ EN AW 3003 material system during a controlled atmosphere brazing process [11].

Magnesium content in aluminium alloys is known to have a negative impact on the potassium fluoroaluminate flux in a brazing cycle. It has been reported that by adding a cesium flux, the negative 
magnesium influence may be relieved to a certain extent $[13,16,17]$. In this study, the flux for brazing EN AW 4047 to EN AW 6061 alloys is a 50-50 vol.\% mixture of a potassium fluoroaluminate flux and a cesium tetrafluoroaluminate flux. Flux deposited to the sample is kept at $\sim 15 \mathrm{~g} / \mathrm{m}^{2}$. Materials and dimensions are summarized in Table IV. Tests for each substrate type are repeated multiple times.

The brazing facility, shown as Fig. 3., enables a controlled atmosphere brazing process inside the hotstage chamber and allows in-situ recording in real time. Facility components include a high temperature hotstage, control units with a computer, a microscope installed with a digital camera, a cooling fluid pump, and a gas supply with a flowmeter. Protective gas in the chamber is maintained by a continuous $99.999 \%$ nitrogen gas supply throughout the processes. Fig. 4. illustrates the test configuration of a sample on the heating element inside the hotstage chamber. A filler disk is placed on a substrate with a prescribed hole. All surfaces of the sample are deposited with the selected flux. The type of flux for each test depends on the material of substrate to be tested, see Table IV for details. Two small sapphire pieces are placed to elevate the sample assembly so that the bottom side of the hole is exposed to nitrogen gas instead of being covered by the sapphire substrate. Fig. 5. presents the temperature history of the tests. In a brazing cycle, the sample stage is heated at the rate of $+100{ }^{\circ} \mathrm{C} / \mathrm{min}$ to $610{ }^{\circ} \mathrm{C}$, dwells for 2 minutes at $610{ }^{\circ} \mathrm{C}$, and then cooled to $40{ }^{\circ} \mathrm{C}$ at the rate of $-100^{\circ} \mathrm{C} / \mathrm{min}$.

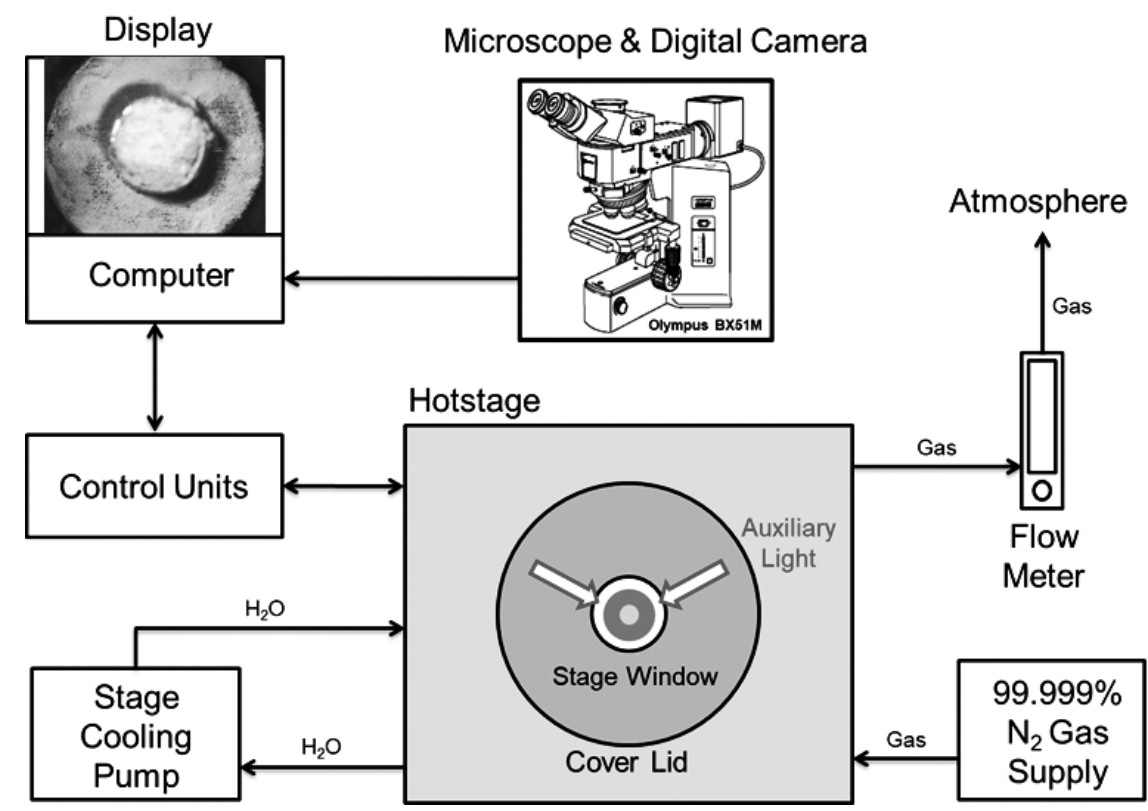

Fig. 3. Brazing facility

Table IV. Materials and dimensions for the aluminium brazing process

\begin{tabular}{ccccc}
\hline Component & Material & Diameter $[\mathbf{m m}]$ & Thickness $[\mathrm{mm}]$ & Flux Type \\
\hline Filler Disk & 4047 & 1.8 & 0.4 & - \\
Substrate Disk 1 & 3003 & 4.0 & 0.4 & $\mathrm{~K}_{1-3}-\mathrm{Al}_{-} \mathrm{F}_{4-6}$ \\
Substrate Disk 2 & 6061 & 4.0 & 0.4 & $\mathrm{~K}_{1-3}-\mathrm{Al}_{-} \mathrm{F}_{4-6}$ and CsAlF $_{4}$ \\
Hole & - & 0.5 & 0.4 & - \\
\hline
\end{tabular}

\section{Friction Stir Spot Welding}

In contrast to the repairing procedure by brazing, the second approach is based on a process without generating liquid phase. By using a solid state process, the damaged parts can be repaired with temperatures below the melting point of both materials [14]. Hence, the advantages of friction stir welding (FSW) and friction stir spot welding (FSSW) are (i) a reduced formation of hot cracks, (ii) a high reproducibility, (iii) the avoidance of pores and (iv) the strength properties similar to the base material [15]. A concept based on friction stir spot welding is used with the aim to use minimal welding forces to compensate the absence of a backing plate in the later application and to use a pin-less tool to avoid further damage in the form of an end hole. 


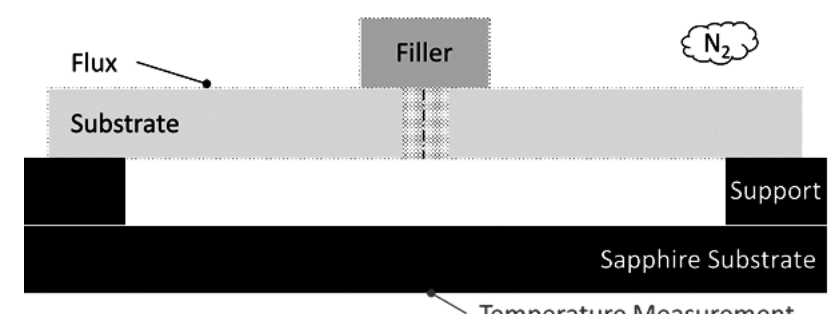

Fig. 4. Test configuration for brazing tests

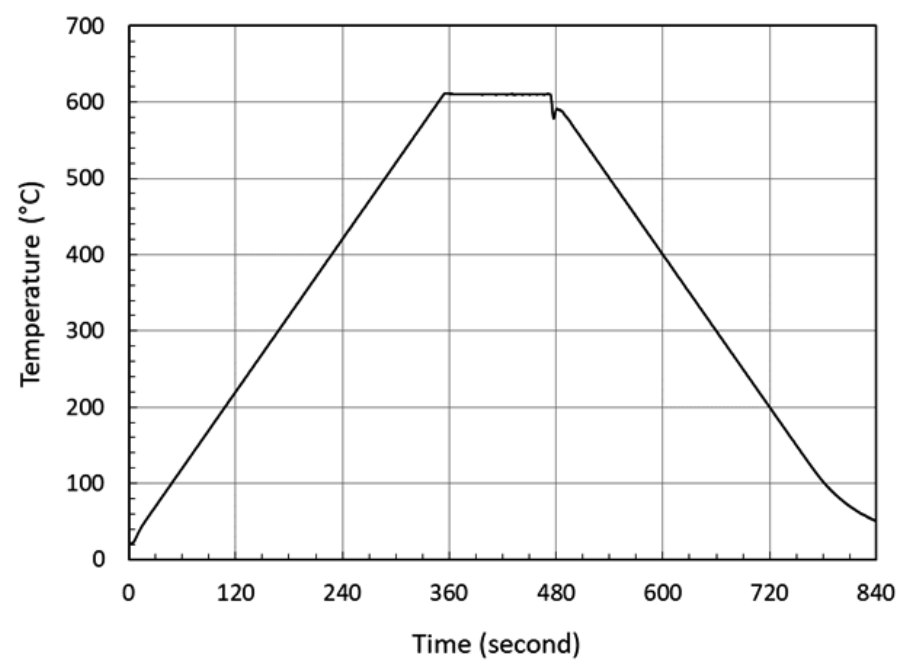

Fig. 5. Temperature profile

In friction stir spot welding, the friction of the tool generates a targeted heat input into an element. Due to the set welding force, the tool penetrates into the material. Hence, the material is plastically deformed. Due to the heat and the plastic deformation the diffusion is accelerated, and a material locking is generated. The goal is to close damages such as holes in structures in space with similar to identical material properties to the base material. The heat input into the material shall be used in such a targeted manner that the mechanical properties of the damaged component remain unchanged due to the influence of the welding temperature. A schematic representation of the FSSW process for repairing holes in structures is shown in Fig. 6. In this concept, the energy is to be introduced into the repair material by direct heat input and plastic deformation. The tool stirs directly on the repair material (Fig. 6.) and pushes it into the defect. Due to the high degree of deformation in the repair material, a connection mechanism based on solid phase diffusion takes place.
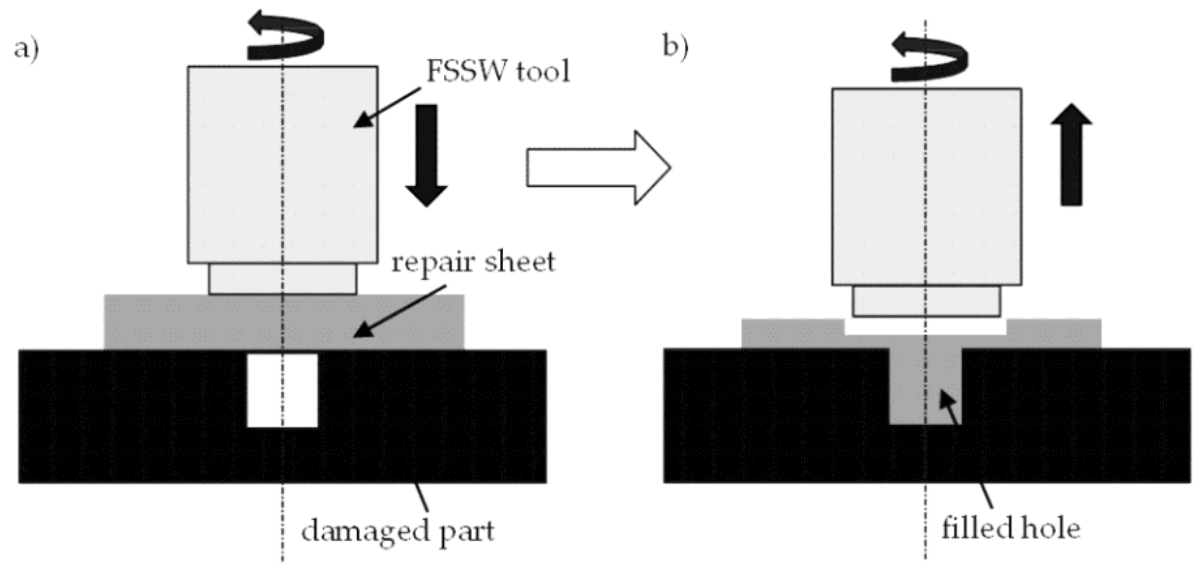

Fig. 6. Schematic illustration of the FSSW repair process of manmade structures in space

The investigations about FSSW were carried out on a force-controlled friction element welding machine of the type RES 38/155 RRS C2 of the manufacturer EJOT Tambach GmbH, which was modified by Ilmenauer Fertigungstechnik (IFt), Technische Universität Ilmenau. This System is characterized by a maximum rotational speed of $80001 / \mathrm{min}$ and a maximum welding force of $6 \mathrm{kN}$. The diameter of the FSSW tool amounts to $10 \mathrm{~mm}$ (Fig. 8.)) and the material of the used tool was WLa 10 (Table. III). The structure of the experimental setup can be seen in Fig. 7. 


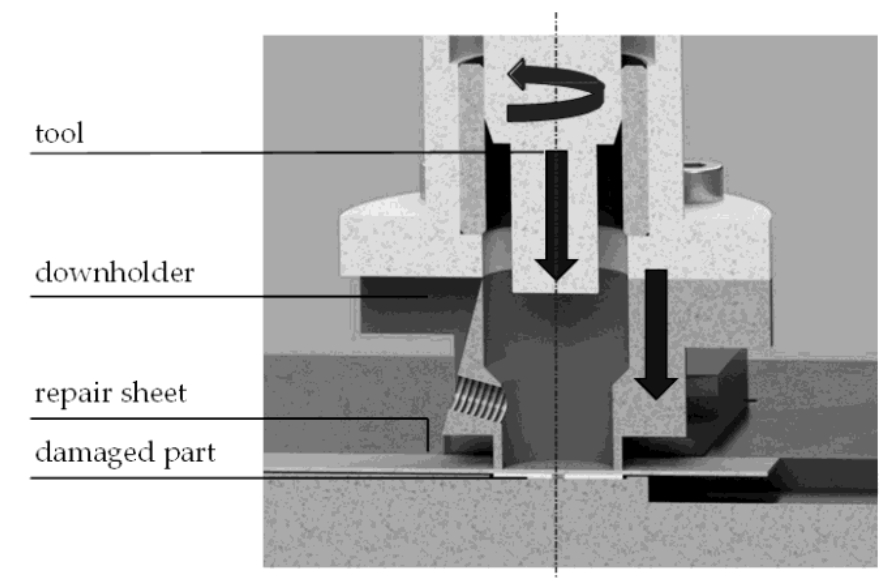

Fig. 7. Cross section of the experimental setup of the FSSW repair process

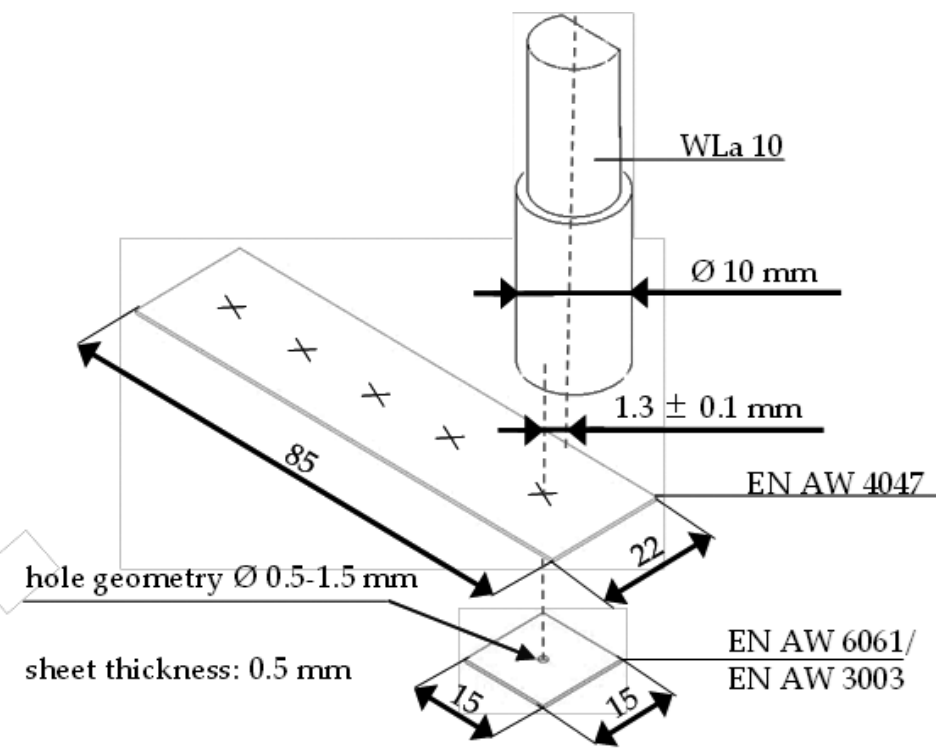

(a)

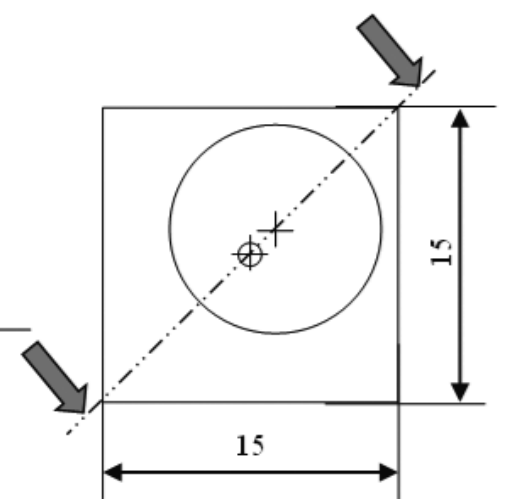

(b)

Fig. 8. a) Experimental Setup of the arrangement of the samples; b) illustration of the cutting plane for the metallographic cross section

During the process, the downholder clamps the position of the samples with a preset clamping force. After that the tool, which is guided by a sliding bush inside the downholder, moves in the axial direction towards the specimen and starts the welding process when a preset trigger force is reached. Due to the forcecontrol of the system, the force is kept constant until a certain abort criterion is reached. In this study a time weld was used.

In Fig. 8a the experimental setup as well as the sample configuration are shown. The EN AW 4047 repair sheet was designed for using up to five repair welds. The specimen with the hole geometry $(0.5 \mathrm{~mm} \div 1.5 \mathrm{~mm})$ was designed with an edge length of $15 \mathrm{~mm}$ (Fig. 9.). The used sheets were $0.5 \mathrm{~mm}$ thick. As the circumferential speed in the center of the tool is zero, the material in the center would only be heated by the surrounding material and pressed by the axial force. To ensure that the repair material is heated and stirred, an eccentricity of $1.3 \pm 0.1 \mathrm{~mm}$ was set up between the hole axis and the tool axis (a).

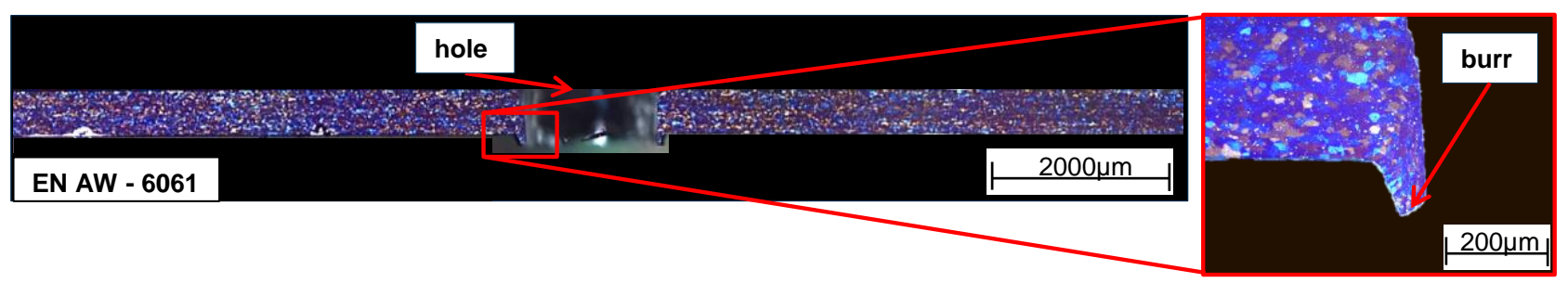

Fig. 9. Cross section of the prepared sample with a $1.5 \mathrm{~mm}$ hole 


\section{Results and Discussion}

\section{Aluminium Brazing}

Samples with either an EN AW 3003 substrate or an EN AW 6061 substrate were tested. Corresponding surface conditions of the sample before assembling, before brazing, and after brazing are registered. Metallographic photos near the hole regions are presented. Fig. 10. shows results for a test containing an EN AW 3003 substrate. Fig. 11. presents the results for a test using an EN AW 6061 substrate. Note that the orange color of the surface flux powder is imposed by an auxiliary halogen light, outside the stage window.

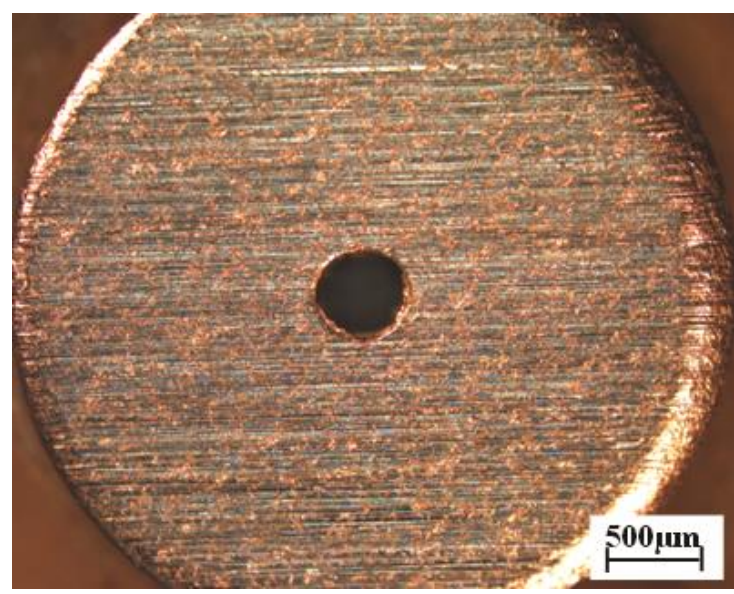

(a)

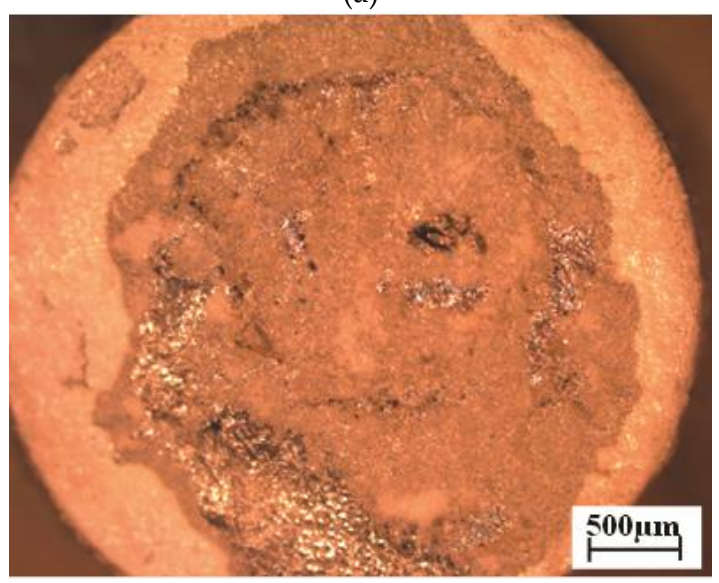

(c)

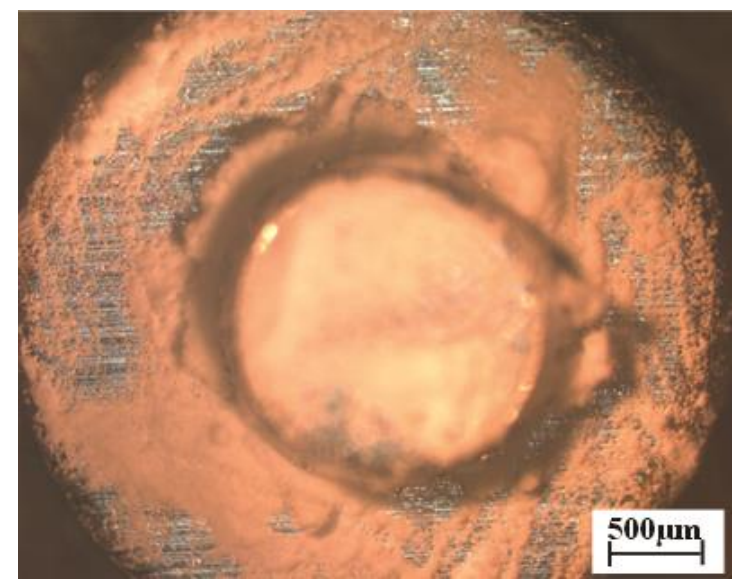

(b)

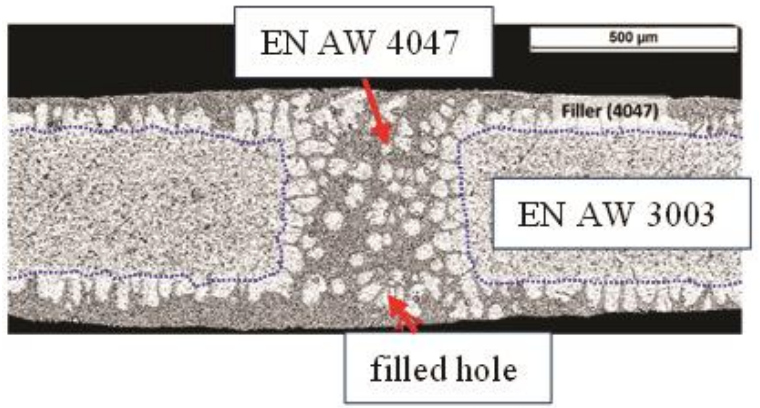

(d)

Fig. 10. Brazing result of the sample with a EN AW 3003 substrate: a) EN AW 3003 sheet with a 0.5 mm hole before brazing; b) surface of the sample assembly of EN AW 4047/ EN AW 3003 system before brazing; c) surface of the sample assembly of EN AW 4047/ EN AW 3003 system after brazing; d) cross-section of the brazed sample

In Fig. 10, in-situ photos from the EN AW 3003 sample show a good wettability over the surface of the substrate. The metallographic photo of the EN AW 3003 sample confirms a filled hole by the re-solidified EN AW 4047 alloy. In Fig. 11. in-situ photos from the EN AW 6061 sample show a limited wettability of the EN AW 4047 filler alloy. The cross-section photo of the brazed EN AW 6061 sample confirms a filled hole, however, a dissolution on the EN AW 6061 substrate, an appearance of cavities upon resolidification, and a large contact angle are registered.

Controlled atmosphere brazing tests have featured bondings for both EN AW 4047/ EN AW 3003 and EN AW 4047/ EN AW 6061 systems. Test results show, as is well known, that the potassium fluoroaluminate flux works well with the molten EN AW 4047 spreading on the EN AW 3003 substrate and filling the hole. The mixed flux of potassium fluoroaluminate flux and cesium tetrafluoroaluminate flux was able to facilitate some spreading of the molten EN AW 4047 filler on the EN AW 6061 substrate. It is shown that a hole on an EN AW 3003 substrate can be successfully repaired by EN AW 4047 in controlled atmosphere brazing process, as expected. On the other hand, to repair a hole on an EN AW 6061 sheet using an EN AW 4047 filler in nitrogen protected atmosphere may be possible but with a limited wettability, noticeable dissolution of the substrate, and a presence of cavities in the joint. Mechanical tests will be investigated next to assess the feasibility of applications. 


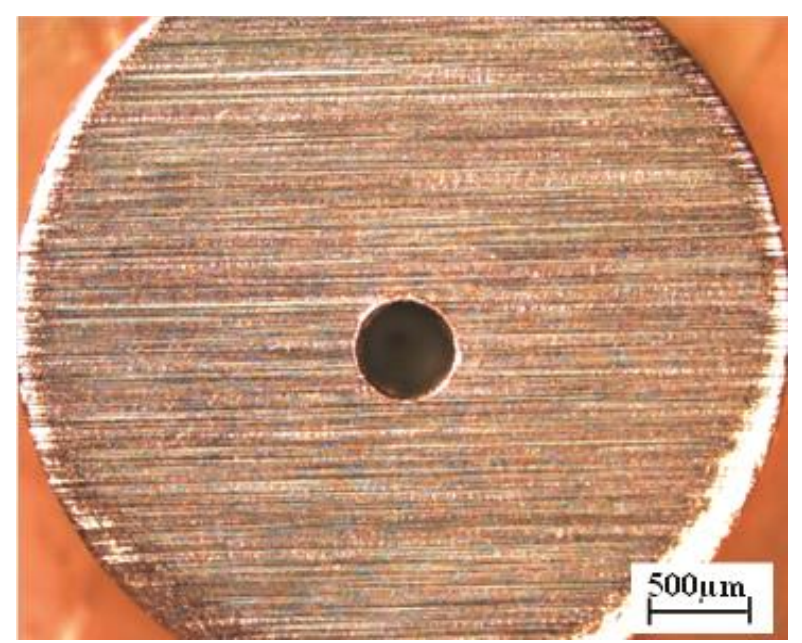

(a)

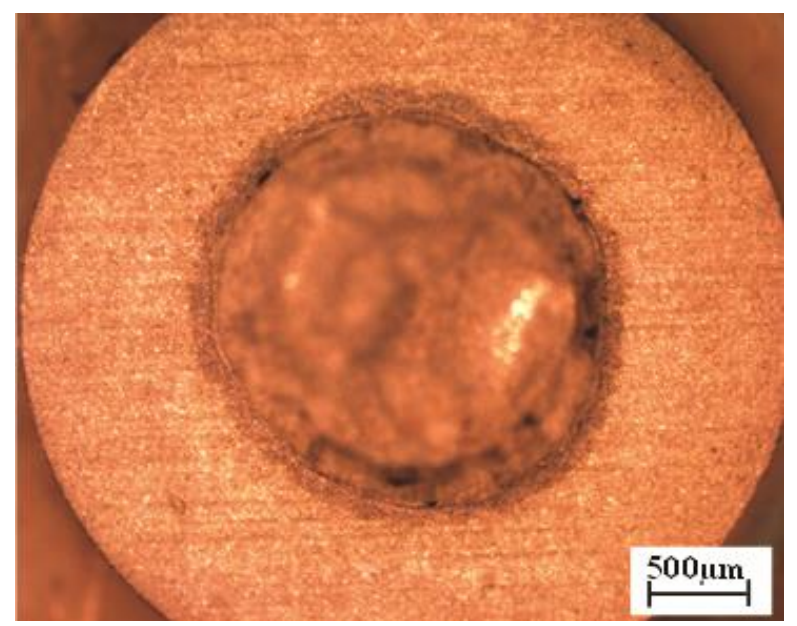

(c)

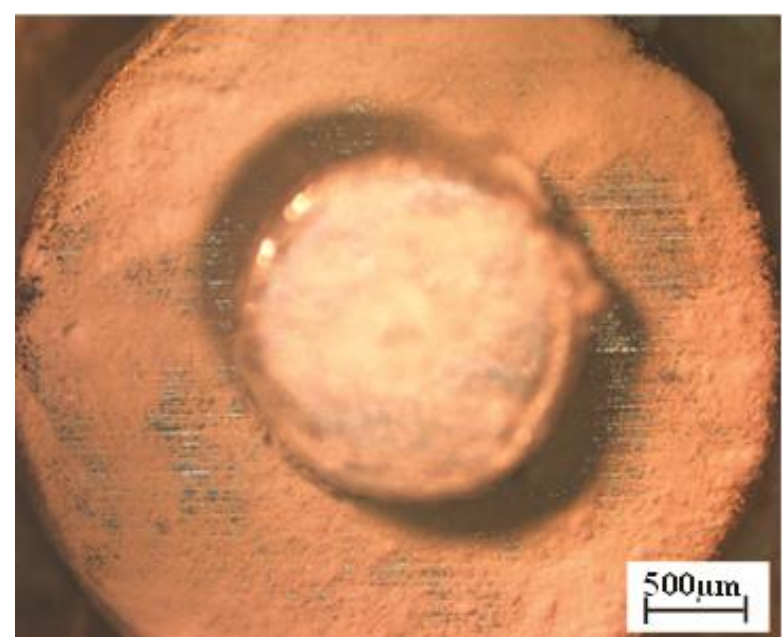

(b)

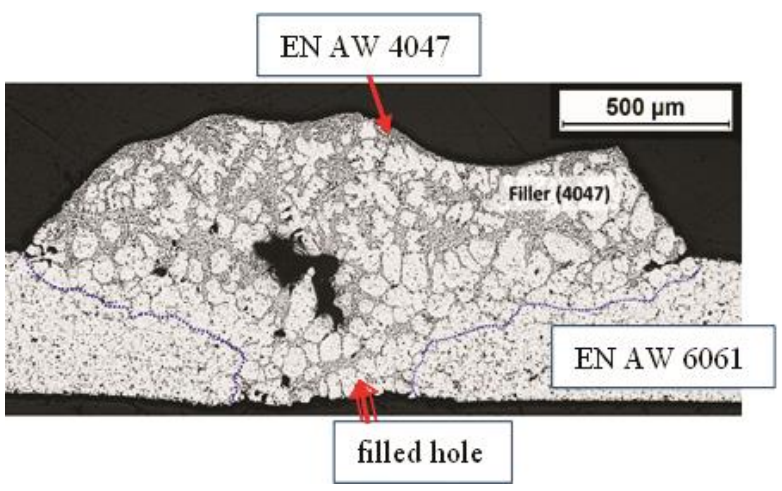

(d)

Fig. 11. Brazing result of the sample with a EN AW 6061 substrate: a) EN AW 6061 sheet with a 0.5 mm hole before brazing; b) surface of the sample assembly of EN AW 4047/ EN AW 6061 system before brazing; c) surface of the sample assembly of EN AW 4047/ EN AW 6061 system after brazing; d) cross-section of the brazed sample

\section{Friction Stir Spot Welding}

In general, the repair process consists of two steps, a welding and a cleaning step. In the first step the materials are joined by frictional heat which leads to plastic deformation and diffusion mechanism between the aluminium alloys. During the welding step, the rotational speed is kept constant at $80001 / \mathrm{min}$. The welding force and the welding time were varied. However, an abrupt ending of the welding step can lead to adhesion behaviour between welding tool and the upper aluminium alloy. In consequence of this, the samples can stick to the tool. To prevent this, the rotational speed is kept constant with a subsequent decrease of the welding force for $0.5 \mathrm{~s}$ in the cleaning step. This prevents adhesion to the tool and ensures smoothness of the surface of the spot weld.

In comparison to the investigation with brazing as repair method, experiments for the combination of EN AW 4047 on EN AW 3003 and the combination of EN AW 4047 on EN AW 6061 were carried out. In the first step, EN AW 4047 was used as repair material whereby EN AW 6061 represents a damaged outer shell structure. The defects are exemplary represented by drilled holes, performed with a diameter of $1.5 \mathrm{~mm}$. The samples were joined by a constant rotational speed of $80001 / \mathrm{min}$ and a welding time of $2.3 \mathrm{~s}$. During the investigation, the welding force was varied from 500 to $1000 \mathrm{~N}$.

In general, it was shown, that the plasticized repair material can fill the hole under atmospheric conditions. It was possible to fill the holes with a comparatively low welding force of $500 \mathrm{~N}$. Considering the hole filling, depicted in Fig. 12a $\div$ d, a significant deformation and grain refinement of EN AW 4047 was found at a constant welding time of $2.3 \mathrm{~s}$. Grain refinement is an effect which occurs, with dynamic recrystallization during hot forming. For dynamic recrystallization a certain temperature and a certain degree of deformation is needed [5]. However, the microstructure of the base material (EN AW 6061) does not undergo any grain 
refinement. This can be seen in the exemplary detailed views in Fig. 12c and Fig. 12d. A tendency to a better filling of the holes with longer welding times is visible in Fig. 13. With a welding time of $1.5 \mathrm{~s}$, it can be seen that the repair material fills the hole not completely. With a longer welding time of $1.9 \mathrm{~s}$, it is possible to fill the hole completely and to generate a bonding between the two materials.

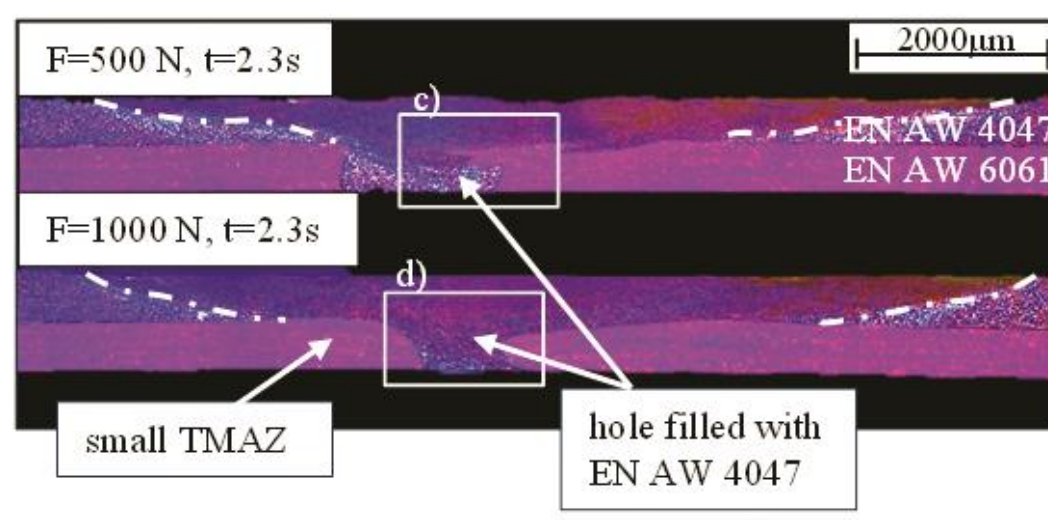

(a) and (b)

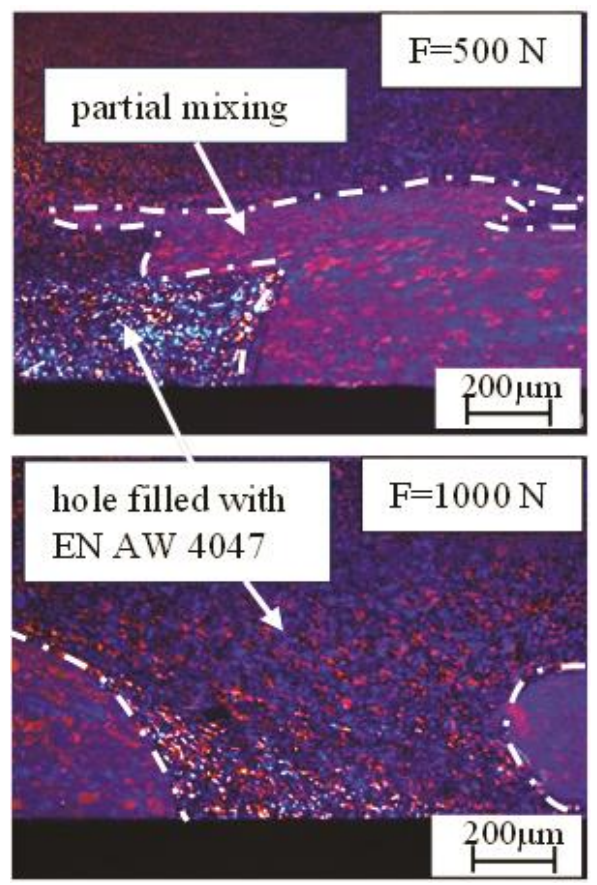

(c) and (d)

Fig. 12. Cross section of EN AW 4047 welded on EN AW $6061(\mathrm{a} \div \mathrm{d})$. Quality of hole filling depending on the welding force: $a) F=500 \mathrm{~N}$; b) $\mathrm{F}=1000 \mathrm{~N}$

In the second step, an aluminium alloy with a lower hardness EN AW 3003 was used as damaged outer shell. EN AW 4047 was used as repair material. The hole in the EN AW 3003 sheet was carried out with a diameter of $0.5 \mathrm{~mm}$. The samples were welded with constant rotational speed of $80001 / \mathrm{min}$, constant welding time of $2.0 \mathrm{~s}$ and varying welding force $(500 \mathrm{~N} ; 1000 \mathrm{~N})$. Fig. 14a $\div \mathrm{d}$ shows the metallographic inspection for welding forces of $500 \mathrm{~N}$ and $1000 \mathrm{~N}$.

In general, a complete hole filling could be achieved for $500 \mathrm{~N}$ and $1000 \mathrm{~N}$. However, varying hole filling and bonding mechanism of EN AW 4047 and EN AW 3003 could be found, compared to the material combination in the previous section. Due to the higher hardness of the EN AW 6061 base material, the repair material is only pressed into the hole. With EN AW 3003 as base material, a mixing of both materials occurs. Hence, the initial hole position is not detectable. Furthermore, in both cases, a grain refinement of EN AW 3003 and EN AW 4047 can be detected from the surface to the bottom side. An increase in the finegrained structure can be explained by improved forming properties of EN AW 3003.

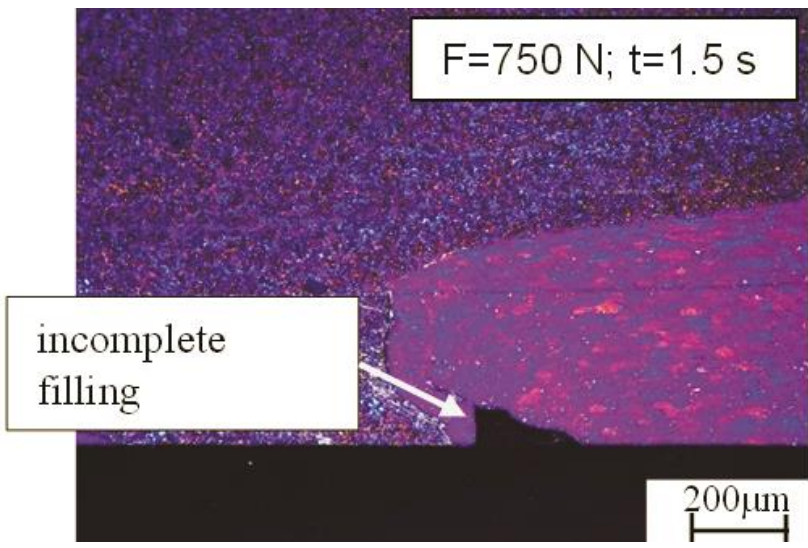

(a)

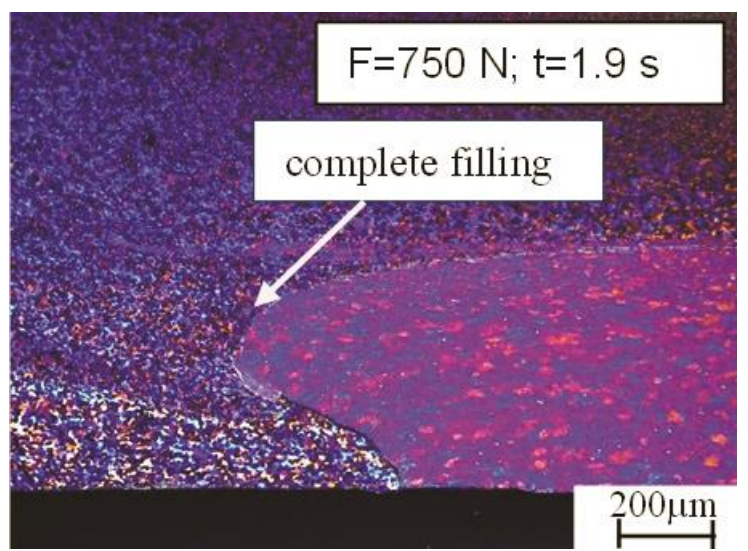

(b)

Fig. 13. Detailed view of the quality of hole filling depending on the welding time at constant rotational speed and constant welding force: a) $t=1.5 \mathrm{~s} ; \mathrm{b}$ ) $\mathrm{t}=1.9 \mathrm{~s}$ 


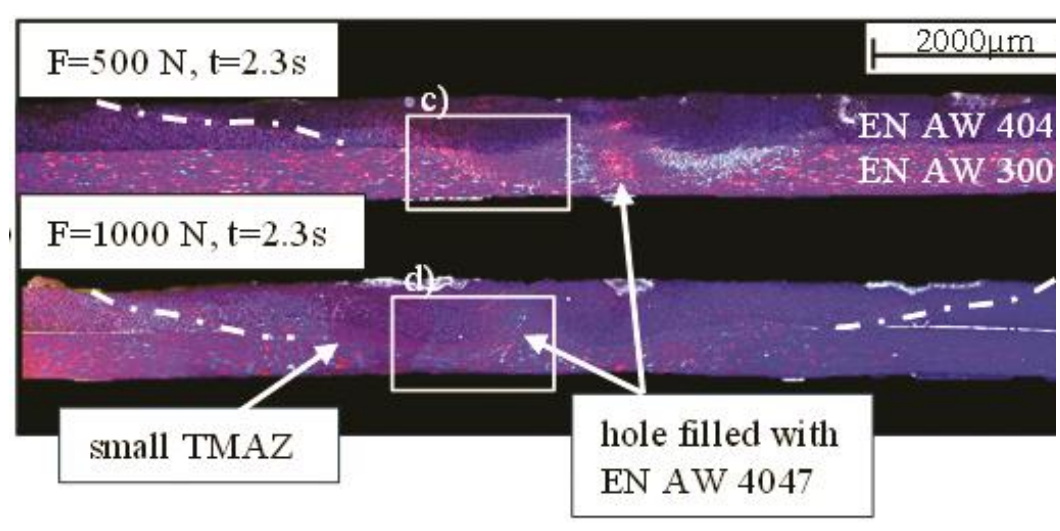

(a) and (b)

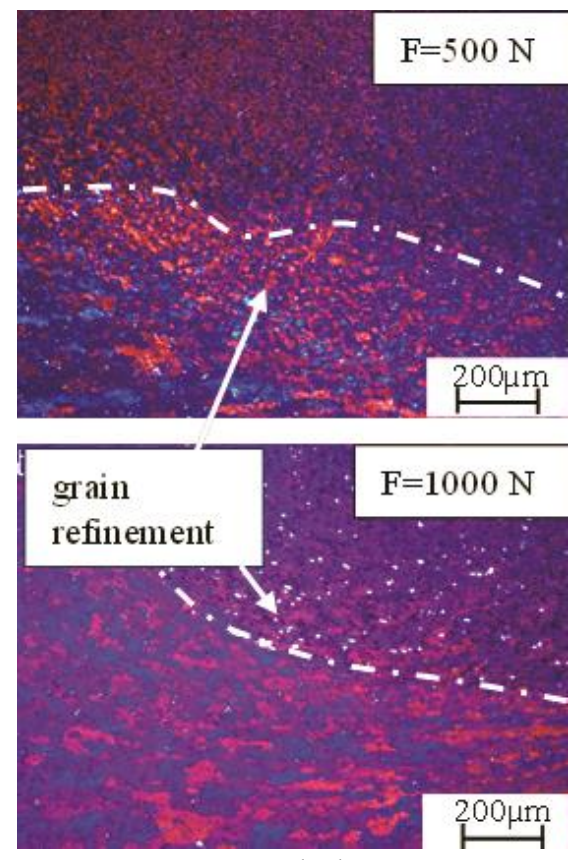

(c) and (d)

Fig. 14. Cross section of EN AW 4047 welded on EN AW $3003(\mathrm{a} \div \mathrm{d})$. Quality of hole filling depending on the welding force: a) $F=500 \mathrm{~N}$; b) $\mathrm{F}=1000 \mathrm{~N}$

\section{Conclusions}

Man-made structures in space are affected by collisions with MMODs. As a result, these impacts can lead to significant damages in the shell structures. Hence a use of appropriate repair techniques is required. In the present study, two different approaches for repairing impacts on different aluminium alloys (EN AW 3003 and EN AW 6061) were investigated. The first approach is using aluminium brazing as repair method. The used repair material is characterized by a lower melting temperature. Hence, by heating the material combination, the upper joining partner will melt before the lower joining partner. The hole then is filled by surface tension driven capillary flow. In general, a prescribed $0.5 \mathrm{~mm}$ diameter hole in a $0.4 \mathrm{~mm}$ thick EN AW 3003 or EN AW 6061 sheet can be filled by an EN AW 4047 filler material in a controlled atmosphere brazing process. The EN AW 3003 case shows excellent joint formation. However, the EN AW 6061 test shows filling but with unfavorable features in terms of wettability and joint integrity.

The second approach is using friction stir spot welding as repair method. This solid-state welding process generates a friction based heat input. Hence, the material is plasticized and pushed into the hole. Due to the generated heat input and the plastic deformation, a diffusion-based material locking is initiated. It was shown that it is possible to repair holes in different base materials like EN AW 6061 and EN AW 3003. Combination EN AW 4047 on EN AW 6061 is characterized by pressing the upper sheet into the hole, whereas combination EN AW 4047 on EN AW 3003 is characterized by stirring both materials, which closes the hole by mixing.

It has been shown that a penetrated hole can be filled/repaired under terrestrial conditions using either aluminium brazing or friction stir spot welding process for selected materials and processing parameters. Advantages and disadvantages of corresponding processes were reported and should be considered for practical applications.

Author Contributions: conceptualization D.P.S., C.-N.Y., J.P.B., T.K. and K.S.; methodology D.P.S., C.-N.Y., J.P.B., T.K. and K.S.; investigation: C.-N.Y., T.K. and K.S.; data acquisition: C.-N.Y., Y.W., T.K. and K.S.; writing - original draft preparation: C.-N.Y. and T.K.; writing - review and editing: D.P.S., Y.W., J.P.B. and M.G.

Funding: The brazing related research was funded by NASA's Physical Sciences Research Program, Grant\# NNX17AB52G.

Acknowledgments: The University of Kentucky team acknowledges continuous discussions with Prof. S. Dj. Mesarovic and Mr. K. Lazaridis (Washington State University, USA) and Prof. M. D. Krivilyov (Udmurt State University, Russia). Technical support from Adam Price, University of Kentucky, is appreciated.

Conflicts of Interest: The authors declare no conflict of interest. 


\section{References}

[1] Laurance M.R., Brownlee D.E., The flux of meteoroids and orbital space debris striking satellites in low Earth orbit, Nature, 1986, 323, 136-138. [CrossRef]

[2] Christiansen E.L., Robinson J.H., Crews J.L. et al., Space station freedom debris protection techniques, Advances in Space Research, 1993, Vol. 13(8) 191-200. [CrossRef]

[3] Barth J.L., Space and Atmospheric Environments: From Low Earth Orbits to Deep Space, In: Kleiman J.I., Iskanderova Z. (eds), Protection of Materials and Structures from Space Environment, 2004, Vol. 5, Kluwer Academic Publishers, Dordrecht, 7-29.

[4] Christiansen E., MMOD Protection and Degration Effects for Thermal Control System, 2014

[5] Roos A., Grundlegende Untersuchung über ein neues Schweißverfahren namens HFDB (Hybrid Friction Diffusion Bonding), GKSS-Forschungszentrum Geesthacht GmbH, 2010, Geesthacht.

[6] Paton B.E., Space: Technologies, materials, structures, Welding and allied processes, 2003, Vol. 2, Taylor \& Francis, London, New York.

[7] Jiang X.-X., Lucier L., Nikanpour D. et al., Determination of the Energy Level of the Atomic Oxygen Flux Generated by the Space Simulation Apparatus Using a Thermal Modeling Method, In: Kleiman J.I., Iskanderova Z. Protection of Materials and Structures from Space Environment, 2004, Vol. 5, Kluwer Academic Publishers, Dordrecht, 359-366.

[8] Robertson S.A., Marshall Researchers Developing Patch Kit to Mitigrate ISS Impact Damage, The Orbital Debris Quarterly News, 1999, Vol. 4(4).

[9] Chaudhary R. Variability reduction and experimental techniques for improving performance of the International Space Station Kit for external Repair of Module Impacts, AIP Conference Proceedings, 2001, 562-567.

[10] Christiansen E.L., Nagy K., Lear D.M. et al., Space station MMOD shielding, Acta Astronautica, 2009, Vol. 65(7-8), 921-929. [CrossRef]

[11] Yu C.-N., Wu Y., Sekulic D.P. Capillary Flow on an Aluminium Brazing Sheet in a Gravity Field: A Phenomenological Study, International Brazing and Soldering Conference, 2018, 29-35.

[12] Yan Q., Zhang X., Wang T. et al., Effect of hot working process on the mechanical properties of tungsten materials, Journal of Nuclear Materials, 2013, Vol. 442(1-3), S233-S236. [CrossRef]

[13] Mirski Z., Pabian J., Modern trends in production of brazed heat exchangers for automotive industry, Welding Technology Review, 2017, Vol. 89(8). [CrossRef]

[14] Grätzel M., Regensburg A., Hasieber M. et al., Scaling effects during friction stir welding of aluminium alloys with reduced tool aspect ratios, Weld World, 2019, Vol. 63(2), 337-347. [CrossRef]

[15] Zhang Y.N., Cao X., Larose S. et al., Review of tools for friction stir welding and processing, Canadian Metallurgical Quarterly, 2012, Vol. 51(3), 250-261. [CrossRef]

[16] Orman L., Swiderski H.W., Lauzon D., Brazing of Aluminium Alloys with Higher Magnesium Content using NonCorrosive Fluxes, Aluminium Brazing - News, Knowledge \& Technology http://www.aluminium-brazing.com, (accessed 04.15.2019).

[17] Garcia J., Massoulier C., Faille P., Brazeability of Aluminium Alloys Containing Magnesium by CAB Process Using Cesium Flux, SAE Technical Paper, 2001-01-1763. [CrossRef]

(C) 2019 by the authors. Submitted for possible open access publication under the terms and conditions of the Creative Commons Attribution (CC BY) license (http://creativecommons.org/licenses/by/4.0/). 